\title{
The Superior Surface Discharge Capacity of Core-Shell Tinoxide/Multi Walled Carbon Nanotube Nanocomposite Anodes for Li-Ion Batteries
}

\begin{abstract}
H. Akbulut*, M. Alaf and D. Gultekin
Sakarya University, Metallurgical and Materials Engineering, Esentepe Campus, 54187, Sakarya, Turkey

In this study, tin/tinoxide/multiwalled carbon nanotube $\left(\mathrm{Sn} / \mathrm{SnO}_{2} / \mathrm{MWCNT}\right)$ nanocomposites were produced as anode materials for $\mathrm{Li}$-ion batteries by a two-step process. Metallic tin was evaporated onto free-standing MWCNT buckypapers having controlled porosity and subsequently rf plasma oxidized in Ar: $\mathrm{O}_{2}$ (1:1) gas mixture. Besides, $\mathrm{Sn} / \mathrm{SnO}_{2}$ nanocomposites were produced in the same conditions onto stainless steel substrates to make a comparison. X-ray diffraction and scanning electron microscopy were used to determine the structure and morphology of the obtained nanocomposites. The discharge/charge tests, cyclic voltammetry and electrochemical impedance spectroscopy were carried out to characterize the electrochemical properties of these composites. Promising results were obtained in the tin based MWCNT nanocomposites for next-generation micro battery applications because of the high active surface area of the $\mathrm{SnO}_{2} / \mathrm{MWCNT}$ core-shell structures.
\end{abstract}

DOI: $10.12693 /$ APhysPolA.125.335

PACS: 81.05.uj, 61.48.De, 82.47.Aa, 82.80.Fk

\section{Introduction}

Developing new generation of electrode materials for lithium-ion batteries (LIBs) with higher-energy density and better rate capability is nowadays very attractive for application such as portable electronic devices and electric vehicles [1-3]. Three-dimensional (3D) architectures with high-aspect-ratios are potentially useful among the new-generation electrodes [4]. 3D batteries are shown significant advantages such as the same footprint and enable shorter diffusion for lithium ions in comparison to $2 \mathrm{D}$ thin-film batteries for powering devices [5].

$\mathrm{SnO}_{2}$ with high theoretical lithium storage capacity is one of the most promising alternative anodes, owing to its high theoretical lithium storage capacity. However, large-volume changes and agglomeration of tin nanocrystals during the alloying and de-alloying processes with lithium profoundly affect the capacity retention [1]. In order to eliminate the volume changes of $\mathrm{SnO}_{2}$, combining Sn-based material with $\mathrm{Sn}$-based oxide materials to form composite electrodes is one of the solutions. Another effective strategy to alleviate this problem is to disperse tin-based materials in a carbon matrix or encapsulates them with carbon. Among them, the $\mathrm{SnO}_{2} /$ carbon nanotube (CNT) composites have attracted considerable research effort [6-8].

In this study, $3 \mathrm{D} \mathrm{Sn} / \mathrm{SnO}_{2} / \mathrm{MWCNT}$ nanocomposite electrode was prepared by a two-step process (thermal evaporation and subsequent plasma oxidation) with using MWCNT buckypaper. For comparison, $\mathrm{Sn} / \mathrm{SnO}_{2}$ nanocomposite thin film electrode was deposited onto the stainless steel substrate. Besides, microstructural and

* corresponding author electrochemical properties of the nanocomposites were investigated to search the application possibility of these electrodes for Li-ion microbatteries.

\section{Experiment details}

The MWCNTs supplied from Arry Nano (Germany) was employed in this work. Purification and chemical oxidation of MWCNTs was carried out with different oxidation agents [9]. Aqueous MWCNTs suspension was sonicated for $1 \mathrm{~h}$ to form a well dispersed suspension which was subsequently vacuum filtered through PVDF membrane filters of $220 \mathrm{~nm}$ pore size to form buckypapers. After drying at room temperature in a vacuum oven for $24 \mathrm{~h}$ the MWCNT buckypapers were peeled off from the filtration membrane.

High purity metallic tin was thermally evaporated, in the first step, onto stainless steel substrates and the buckypapers to produce Sn thin films and Sn/MWCNT nanocomposites. Evaporation time is $1 \mathrm{~min}$ for $\mathrm{Sn} / \mathrm{MWCNT}$ nanocomposites. Sn thin films in the thickness of $500 \mathrm{~nm}$ were deposited onto stainless steel substrates. In the second step, Sn films and Sn/MWCNT nanocomposites were subjected to RF plasma oxidation process using oxygen and argon gas mixture in the ratio of $1: 1$ for $1 \mathrm{~h}$. The detailed experimental work, effects of evaporation time and plasma oxidation times on structural and electrochemical properties were provided in our previous study [10].

An XRD (Rigaku D/MAX 2000) with $\mathrm{Cu} K_{\alpha}$ radiation has been used to determine the composition, relative phase amounts and structure of the nanocomposites. Transmission electron microscopy (TEM, Tecnai $\mathrm{G}^{2}$ F20 S-TWIN) and field emission gun (FEG-SEM, JEOL $6335 \mathrm{~F}$ ) were used for examining surface morphologies. TEM samples of the anode paper were prepared by removing a small piece from the paper and mounting it on a folding copper mesh oyster grid. Coin-type (CR2016) 
test cells were assembled in an argon-filled glove box and the details of the CR2016 button type cell assembling can be found in our previous work [10].

\section{Results and discussions}

The buckypapers were successfully produced from chemically oxidized MWCNT as flexible, uniform, smooth and crack-free disks and easily peeled-off from PVDF membrane [10]. Highly porous buckypaper structures were obtained to provide a large surface proper to the thin film electrode for microbatteries. Figure 1a shows a typical XRD pattern and SEM image for the double phase $\mathrm{Sn} / \mathrm{SnO}_{2}$ nanocomposite thin film that was produced with thermal evaporation and subsequent plasma oxidation (Sn: JCPDS No. 01-089-2958 and $\mathrm{SnO}_{2}$ : JPDS No. 00-041-1445). Surface morphology of the nanocomposite thin film refers to conventional $\mathrm{SnO}_{2}$ structure [11]. $\mathrm{Sn} / \mathrm{SnO}_{2} / \mathrm{MWCNT}$ nanocomposite electrode produced with thermal evaporation of metallic tin onto MWCNT buckypaper and subsequent plasma oxidation process under Ar: $\mathrm{O}_{2}$ (1:1) atmosphere was analyzed by XRD and SEM. Structural characterization results of $\mathrm{Sn} / \mathrm{SnO}_{2} / \mathrm{MWCNT}$ nanocomposite are presented in Fig. 2b. Diffraction peaks at $26^{\circ}$ and $33^{\circ}$ correspond to $\mathrm{SnO}_{2}$ (JCPDS No. 00-041-1445) while the peak at $45^{\circ}$ is for Sn (JCPDS No. 01-089-2958). It should be noted that a diffraction peak at around $26^{\circ}$, which is the main peak of tetragonal $\mathrm{SnO}_{2}$ (110) almost overlaps with the main peaks of hexagonal $\mathrm{C}(002)$ as also defined in the different works [12].
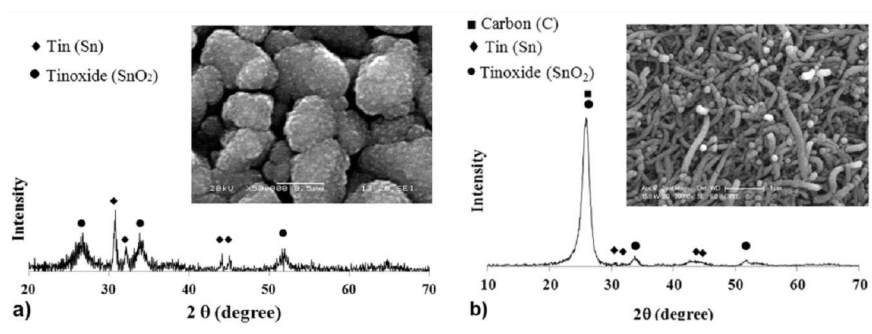

Fig. 1. XRD pattern and SEM images of $\mathrm{Sn} / \mathrm{SnO}_{2}$ nanocomposite thin films on: (a) stainless steel and (b) MWCNT.

$\mathrm{Sn} / \mathrm{SnO}_{2} / \mathrm{MWCNT}$ nanocomposite electrode was examined using EDS mapping analyzing from cross-section area, and the result is presented in Fig. 2. Sn rich layer depth is about $5 \mu \mathrm{m}$ and evaporated tin is mainly introduced between the MWCNTs and resulted in coating the MWCNT surfaces with remaining a significant porosity between the MWCNTs as channels. It can be concluded from the dot-map analysis that Sn shows a gradient composition through the center of buckypaper. It is well known that the gradient phase distribution in the composites is beneficial for decreasing crack initiation and therefore, failure [13]. High magnification FE-SEM image and TEM structure is given in Fig. 3a and b to illustrate the core-shell structure of the $\mathrm{Sn} / \mathrm{SnO}_{2} / \mathrm{MWCNT}$ nanocomposite electrode. Because of the double phase structure of $\mathrm{Sn} / \mathrm{SnO}_{2}$, the core shell structure exhibits

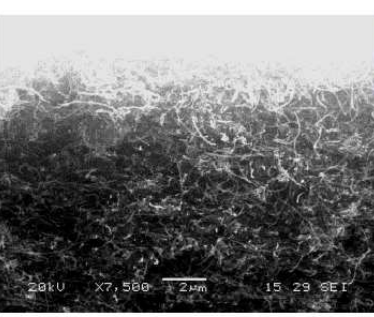

口
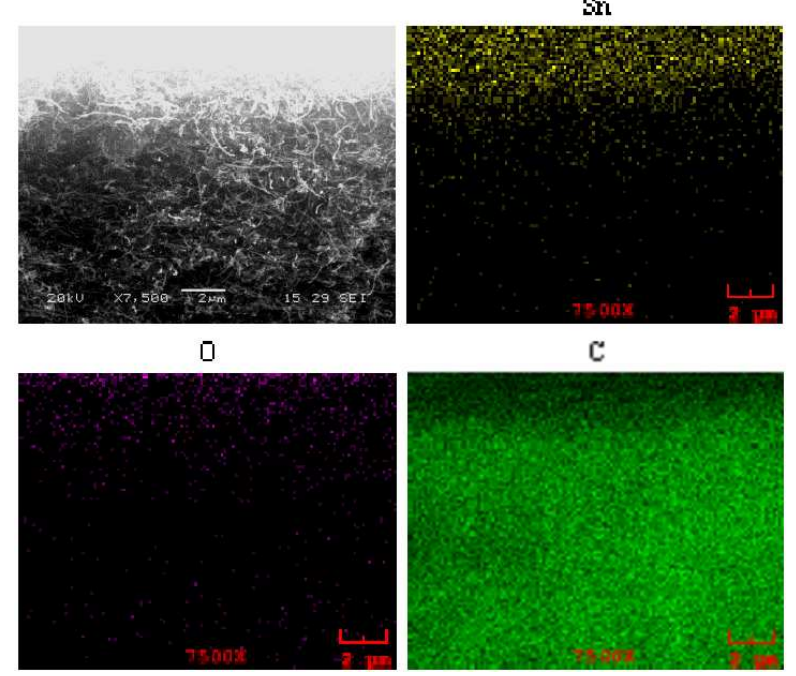

C

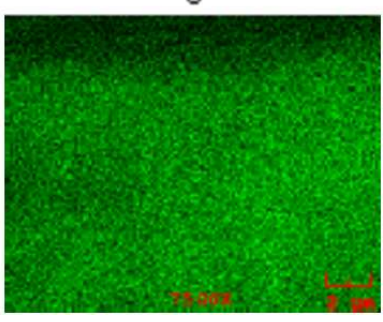

Fig. 2. SEM-energy dispersive spectroscopy (SEMEDS) dot-map analysis results for $\mathrm{Sn} / \mathrm{SnO}_{2} / \mathrm{MWCNT}$ nanocomposite from cross-section.
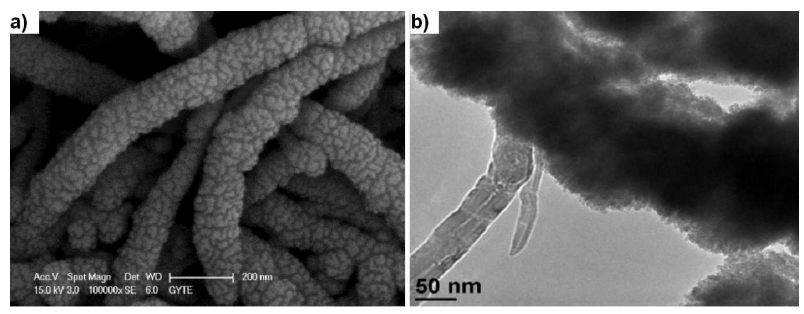

Fig. 3. Core-shell structures of $\mathrm{Sn} / \mathrm{SnO}_{2} / \mathrm{MWCNT}$ nanocomposites: (a) FE-SEM image, (b) TEM image.

three layers. The structure contains MWCNT at the center, $\mathrm{Sn}$ on MWCNT and $\mathrm{SnO}_{2}$ on the $\mathrm{Sn}$ phase.

Cyclic voltammetry $(\mathrm{CV})$ measurements at a scan rate of $0.2 \mathrm{mV} \mathrm{s}^{-1}$ were performed to examine the electrochemical properties of electrodes during the charge-discharge process for the first three cycles. Results of cyclic voltammetry of $\mathrm{Sn} / \mathrm{SnO}_{2}$ nanocomposites thin film and $\mathrm{Sn} / \mathrm{SnO}_{2} / \mathrm{MWCNT}$ nanocomposite electrodes are shown in Fig. 4. In Fig. 4a, the small cathodic peak around $1.34 \mathrm{~V}$ and the peaks at $0.34 \mathrm{~V}$ are due to the reduction of $\mathrm{SnO}_{2}$ to metallic $\mathrm{Sn}$ and the solid electrolyte interface (SEI) formation during the first discharge at $0.7 \mathrm{~V}$. The cathodic peaks below $0.4 \mathrm{~V}$ are due to formation of the $\mathrm{Li}_{x} \mathrm{Sn}$ alloy. The anodic peak at $0.63 \mathrm{~V}$ corresponds to the de-alloying reaction of $\mathrm{Li}_{x} \mathrm{Sn}$. These two reactions are fully reversible. In Fig. $4 \mathrm{~b}$, the strong peak at $0.53 \mathrm{~V}$ and disappear after first discharge process is due to the formation of the SEI layer. The reduction peak within the range of $0.7-1.2 \mathrm{~V}$ corresponds to decomposition of $\mathrm{SnO}_{2}$ to become $\mathrm{Sn}$, which only happens in the first discharge cycle. An oxidation peak at $0.5 \mathrm{~V}$ corresponds to the reversible formation of $\mathrm{Li}_{x} \mathrm{Sn}$ alloys.

Figure 5a shows the corresponding capacity per $\mathrm{cm}^{2}$ (geometric area) vs. cycle number for cells made 

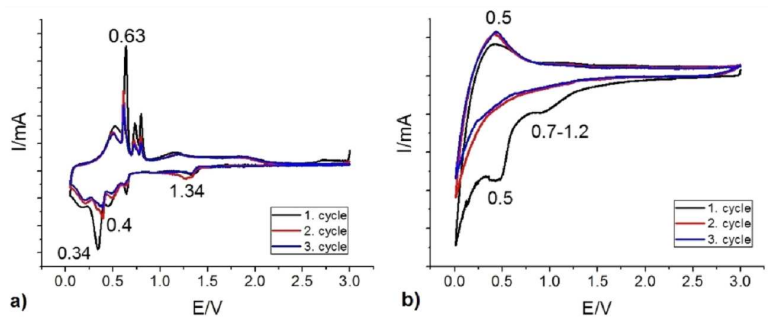

Fig. 4. Cyclic voltammograms for the first 3 cycles of the electrodes: (a) $\mathrm{Sn} / \mathrm{SnO}_{2}$, (b) $\mathrm{Sn} / \mathrm{SnO}_{2} / \mathrm{MWCNT}$.

TABLE

Electrochemical impedance parameters of calculated from the equivalent circuit model.

\begin{tabular}{c|c|c|c}
\hline \hline & Circuit model & $R_{\mathrm{s}}[\Omega]$ & $R_{\mathrm{ct}}[\Omega]$ \\
\hline $\mathrm{Sn} / \mathrm{SnO}_{2}$ & {$[\mathrm{R}(\mathrm{CR})(\mathrm{QR})(\mathrm{CR})]$} & 5.55 & 397 \\
$\mathrm{Sn} / \mathrm{SnO}_{2} / \mathrm{MWCNT}$ & {$[\mathrm{R}(\mathrm{Q}(\mathrm{RW}))]$} & 7.51 & 257
\end{tabular}

from $\mathrm{Sn} / \mathrm{SnO}_{2}$ nanocomposite thin film and $\mathrm{Sn} / \mathrm{SnO}_{2} /$ MWCNT nanocomposite electrodes. Compared with the $\mathrm{Sn} / \mathrm{SnO}_{2}$ double phase structures on the stainless steel coin electrode, the $\mathrm{Sn} / \mathrm{SnO}_{2} / \mathrm{MWCNT}$ nanocomposite showed outstanding performance with high capacity and satisfactory cycling stability. Even at 100 cycles no cell failure was detected on all the studied cell assemblies. Electrochemical impedance spectroscopic (EIS) measurements were carried out to confirm the effect of MWCNTs on changing the charge transfer resistance in $\mathrm{Sn} / \mathrm{SnO}_{2}$ and $\mathrm{Sn} / \mathrm{SnO}_{2} / \mathrm{MWCNT}$ nanocomposite electrodes using a sine wave of $10 \mathrm{mV}$ amplitude over a frequency range of $100 \mathrm{kHz}$ to $0.1 \mathrm{~Hz}$. Figure 5b shows the Nyquist plots and Table shows electrochemical impedance parameters obtained from the Li-ion cells before testing the electrochemical performance.
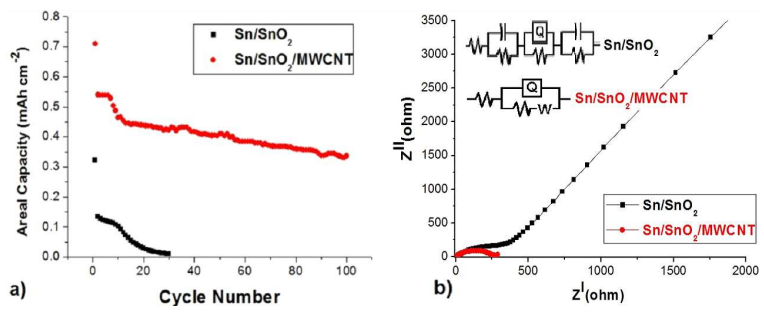

Fig. 5. (a) Areal capacity evolution of $\mathrm{Sn} / \mathrm{SnO}_{2}$ and $\mathrm{Sn} / \mathrm{SnO}_{2} / \mathrm{MWCNT}$ nanocomposite electrodes as a function of cycle number. (b) Electrochemical impedance spectra of $\mathrm{Sn} / \mathrm{SnO}_{2}$ and $\mathrm{Sn} / \mathrm{SnO}_{2} /$ MWCNT nanocomposite electrodes.

\section{Conclusions}

The 3D double phase $\mathrm{Sn} / \mathrm{SnO}_{2} / \mathrm{MWCNT}$ nanocomposite electrode was successfully produced by a two-step process. For comparison, structural and electrochemical properties of $\mathrm{Sn} / \mathrm{SnO}_{2}$ nanocomposite thin film electrode on stainless steel were also tested. Thermally evaporated tin was effectively impregnated into buckypaper with deposition on the MWCNT surfaces revealing a core-shell structure. The process yielded a functionally gradient structure, which results in increasing stress distribution and prevent electrode pulverization. $\mathrm{Sn} / \mathrm{SnO}_{2} / \mathrm{MWCNT}$ nanocomposite showed outstanding performance with high capacity and satisfactory cycling stability. Even at 100 cycles no cell failure was detected on all the studied cell assemblies. Extremely high discharge capacity of nanocomposite electrodes makes them good candidates for possible microbattery applications.

\section{Acknowledgments}

The authors would like to acknowledge the financial support of Scientific and Technical Research Council of Turkey (TÜBİTAK) under the contract number 109M464 and Sakarya University, Coordination of Scientific Research Project (BAPK) under the contract number 2010$-50-02-017$.

\section{References}

[1] L. Noerochim, J. Wang, S. Chou, H. Li, H. Liu, Electrochim. Acta 56, 314 (2010).

[2] S. Ni, T. Li, X. Lv, X. Yang, L. Zhang, Electrochim. Acta 91, 267 (2013).

[3] S. Ni, X. Lv, T. Li, X. Yang, L. Zhang, Y. Ren, Electrochim. Acta 96, 253 (2013).

[4] A.V. Jeyaseelan, J.F. Rohan, Appl. Surf. Sci. 256S, 61 (2009).

[5] F. Wang, S. Xu, S. Zhu, H. Peng, R. Huang, L. Wang, X. Xie, P.K. Chu, Electrochim. Acta 87, 250 (2013).

[6] S. Han, B. Jang, T. Kim, S.M. Oh, T. Hyeon, Adv. Funct. Mater. 15, 1845 (2005).

[7] Y. Kim, Y. Yoon, D. Shin, J. Anal. Appl. Pyrol. 85, 557 (2009).

[8] Y. Fu, R. Ma, Y. Shu, Z. Cao, X. Ma, Mater. Lett. 63, 1946 (2009).

[9] U. Tocoglu, M. Alaf, O. Cevher, M.O. Guler, H. Akbulut, J. Nanosci. Nanotechnol. 12, 9169 (2012).

[10] M. Alaf, D. Gultekin, H. Akbulut, Appl. Surf. Sci. 275, 244 (2013).

[11] M. Alaf, M.O. Guler, D. Gultekin, M. Uysal, A. Alp, H. Akbulut, Vacuum 83, 292 (2008).

[12] W. Han, A. Zettl, Nano Lett. 3, 681 (2003).

[13] M.T. Tilbrook, R.J. Moon, M. Hoffman, Compos. Sci. Technol. 65, 201 (2005). 